\title{
Knowledge and Attitudes Towards Rotavirus \\ Diarrhea and the Acceptance of Rotavirus Vaccination Amongst Primary Caregivers in Yogyakarta, Indonesia: A Qualitative Study
}

Mei Sitaresmi ( $\sim$ msitaresmi@ugm.ac.id )

Gadjah Mada University

Holly Seale

UNSW Sydney

Anita Heywood

UNSW Sydney

Retna Padmawati

Gadjah Mada University

Yati Soenarto

Gadjah Mada University

Raina MacIntyre

UNSW Sydney

Jarir Atthobari

Gadjah Mada University

Research Article

Keywords: vaccine acceptance, knowledge, primary caregiver, rotavirus

Posted Date: January 18th, 2021

DOI: https://doi.org/10.21203/rs.3.rs-136712/v1

License: (c) (i) This work is licensed under a Creative Commons Attribution 4.0 International License.

Read Full License 


\section{Knowledge and attitudes towards rotavirus diarrhea and the acceptance of rotavirus}

2 vaccination amongst primary caregivers in Yogyakarta, Indonesia: a qualitative study

3 Mei N. Sitaresmia, ${ }^{a}$, Holly Seale ${ }^{b}$, Anita E. Heywood ${ }^{\mathrm{C}}$, Retna S. Padmawatid ${ }^{\mathrm{d}}$, Yati Soenarto ${ }^{\mathrm{a}}$, C

4 Raina Maclntyre ${ }^{\mathrm{e}}$, Jarir Atthobari ${ }^{\dagger}$

6 Authors' affiliations

7 a Department of Child Health, Faculty of Medicine, Public Health and Nursing, Universitas Gadjah

8 Mada (UGM)/ RSUP DR Sardjito, Yogyakarta, Indonesia

9 b School of Population Health, UNSW Sydney, Australia

$10{ }^{\mathrm{c}}$ School of Public Health and Community Medicine, UNSW Australia

$11{ }^{\mathrm{d}}$ Department of Health Behavior, Environment, and Social Medicine, Faculty of Medicine, Public

12 Health and Nursing, Universitas Gadjah Mada (UGM), Yogyakarta, Indonesia

13 e Biosecurity Program, The Kirby Institute, UNSW,

$14 \mathrm{f}$ Department of Pharmacology and Therapy, Faculty of Medicine, Public Health and Nursing,

15 Universitas Gadjah Mada (UGM), Yogyakarta, Indonesia

16 g Correspondence: msitaresmi@ugm.ac.id, Jalan Affandi CT X no 18 Pelemkecut, Yogyakarta,

17 Indonesia, Code post 55281

19 Email Addresses:

20 Mei Neni Sitaresmi : : msitaresmi@ugm.ac.id

21 Holly Seale : $\underline{\text { h.seale@unsw.edu.au }}$

22 Anita Heywood : a.heywood@unsw.edu.au

23 Siwi Padmawati : rspadmawati@ugm.ac.id

24 Yati Soenarto : ysoenarto@ugm.ac.id

25 C Raina Maclntyre : r.macintyre@unsw.edu.au

26 Jarir Atthobari : j.atthobari@gmail.com 
27 Running title : Acceptance of rotavirus vaccination amongst primary caregivers in Yogyakarta, 28 Indonesia

29

30 Word count : Abstract: 285; Manuscript: 2941

$31 \quad$ Number table : 2

32 


\section{ABSTRACT}

34 Background: Rotavirus is the leading cause of hospitalized diarrhea in Indonesia. Rotavirus

35 vaccine has not been included on the Indonesian National Immunization Program (NIP). There

36 are some key issues must be considered before introducing a new vaccine into a NIP. Our study

37 aimed to explore the knowledge and attitudes of rotavirus diarrhea and barriers to the acceptance

38 of the vaccine.

39 Methods: We conducted 26 in-depth interviews in two districts (rural and urban areas) of

40 Yogyakarta Province, Indonesia. Participants included pregnant women in their third trimester

41 and mothers of infants aged less than 14 weeks. We conducted a thematic analysis.

42 Results: Participants did not perceive diarrhea as being a priority health problem. Very few had

43 heard of rotavirus diarrhea or were aware of the availability of the vaccine. While participants

44 would accept a vaccine their children against rotavirus, some key barriers impacted the use of

45 the vaccine. As the rotavirus vaccine is not included in the Indonesian National Immunisation

46 Program (NIP), parents perceived it as not essential. Parents were concerned regarding the

47 safety and benefit of the vaccine due to the perceived newness of the vaccine. Other concerns

48 were the vaccine was too costly and the halal issue. Participants expressed a need for more

49 information on the vaccine's effectiveness and safety, with their primary health care providers

50 (HCPs) nominated as playing an important role in vaccine acceptance.

51 Conclusions: There was low awareness of rotavirus being a serious disease and the availability

52 of the rotavirus vaccine in Indonesia. The vaccine is not on the Indonesian NIP, the newness, the

53 safety and efficacy, the cost, and the halal status of vaccine were barriers to vaccine acceptance.

54 Information and recommendation by HCPs play an essential role in vaccine acceptance

55 Key Words: vaccine acceptance, knowledge, primary caregiver, rotavirus 


\section{Background}

Diarrhoeal diseases are one of the leading causes of morbidity and mortality in children

59 younger than five years, cause more than half a million deaths per year globally, with most of

60 them, live in low-middle income countries[1],[2]. A large proportion, $55 \%$ in Asia, and $32 \%$ in

61 Africa, of acute watery diarrhea hospitalizations and $28 \%$ of watery diarrhea deaths are due to

62 rotavirus[3]. The Indonesian Rotavirus Surveillance Network (IRSN) conducted hospital-based

63 surveillance studies across Indonesia from $1978-2015$ and found $38 \%-62 \%$ of watery diarrhea

64 was caused by rotavirus[4],[5],[6],[7]. The estimated total direct medical costs of rotavirus

65 outpatient and inpatient hospitalizations in Indonesia amount to US\$16.7million per year[8].

66 Reinfections with rotavirus are common throughout life, although the disease severity is reduced

67 with repeat infections[9]. The repeated infection at a younger age leads to growth faltering and

68 subsequent, resulting in stunting[10], which is associated with a decrease in cognitive

69 development[11],[12].

Due to the high transmissibility of rotavirus, improvements in sanitation and hygiene are

71 not sufficient to prevent rotavirus disease, and vaccination is the most effective prevention[9]. In

72 2013, World Health Organization (WHO) recommended the inclusion of a rotavirus vaccine into

73 all national immunization programs (NIP), especially in regions with a high mortality rate of

74 rotavirus-associated diarrhea, including South-East Asia[13]. To date, ninety-nine countries have

75 introduced the vaccine, including 73 Gavi-eligible countries[14]. Rotavirus vaccination has the

76 potential to prevent nearly 600000 deaths and to save approximately $\$ 484 \cdot 1$ million from the

77 government perspective and $\$ 878.0$ million from the societal perspective[15]. A recent systematic

78 review (2019) on rotavirus vaccines showed evidence of the vaccine's effectiveness in preventing

79 death caused by rotavirus diseases and vaccine safety, both in developed and developing

80 countries[16]. 
Since 2011, two commercial rotavirus vaccines, RotaTeq® (Merck Vaccines, USA) and

82 Rotarix® (GlaxoSmithKline Biologicals, Belgium), have been licensed in Indonesia and has been

83 recommended by the Indonesian Pediatric Society, however to date, it has not been included on

84 the Indonesian NIP schedule. According to the WHO, some key issues should be considered

85 before introducing a new vaccine into a NIP, including the communities' perceptions of disease

86 severity and susceptibility, vaccine efficacy, and safety[17]. Another issue is the use of porcine

87 trypsin in the manufacturing process. For Indonesia, which has the largest Muslim population in

88 the world, the exploration of cultural and religious aspects of vaccination will inform the national

89 vaccination program and has broader implications for policy development in other Islamic

90 communities [18]. We conducted a qualitative study in Yogyakarta, Indonesia, to explore the

91 knowledge and attitudes to rotavirus diarrhea and barriers to the acceptance of the vaccine of

92 community members, health care providers (HCPs), and other stakeholders. This study reports

93 on the findings from the pregnant women and primary caregivers of infants.

\section{METHODS}

\section{Study design and setting}

97 This qualitative study is a part of a more extensive study exploring the rotavirus vaccine

98 acceptance among three groups: parents (pregnant women in their third trimester and primary

99 caregivers of infants aged less than 14 weeks), HCPs,[19], and key community-religious leaders

100 [18]. This article focuses on pregnant women and parents. We conducted in-depth interviews

101 between August and Octobers 2013 in two districts of Yogyakarta Province: Yogyakarta and

102 Sleman (representing urban and rural areas). Each district consists of several sub-districts, and

103 each sub-district has at least one Primary Health Centre (PHC) responsible for providing primary

104 health care to the surrounding villages. Each village has at least one midwife responsible for 
105 mother and child health services at the village level, including providing NIP vaccines.

\section{Participants and recruitment}

We purposely invited pregnant women in their third trimester and primary caregivers of

108 infants aged less than 14 weeks to participate in the study. The infant age limit reflects the

109 specified cut-off period for the first dose of the rotavirus vaccine. Midwives identified potential

110 participants from the registries of community members and offered them invitation letters and

111 supporting documents at the time of attending the clinic. Follow-up telephone calls were made by

112 the research staff to ascertain if they were interested in participating. Before the interview, they

113 did not know each other.

\section{Data collection}

The authors developed an interview guide based on the literature review. We conducted

116 a weekly team meeting to discuss preliminary findings, and we modified and revised the interview

117 guides as needed. Questions related to the following topics: (1) knowledge and attitudes

118 towards diarrhea, (2) perceptions of susceptibility and disease severity, (3) awareness and

119 acceptance of the rotavirus vaccine; (4) barriers impacting on vaccination and (5) information

120 needs and strategies for the provision of information (Supplementary file). We conducted

121 paraphrasing and asked additional questions to seek clarification during the interviews to ensure

122 that the study included most of the question topics. We provided a brief, standard written

123 explanation of rotavirus diarrhea and the vaccine after ascertaining participant baseline

124 knowledge about rotavirus. Debriefing was done at the end of each interview. We re-contacted

125 participants if further clarification was required. We recruited participants until data was saturated,

126 where no new ideas or issues were raised in subsequent sessions. Two trained and experienced

127 researchers, who were familiar with the data collection method, from the Faculty of Medicine, 
128 Public Health and Nursing, Universities Gadjah Mada (FK-KMK UGM) conducted the interviews

129 in the participants' house for an average of 45 minutes per interview. No observers were present.

130 The Medical and Health Research Ethics Committee (MHREC) FK-KMK UGM ((KE/FK/689/EC)

131 and University of New South Wales, Australia (HC13079) approved the study. We obtained

132 informed consent from all participants at the time of the interview, and we assured confidentially.

133 We conducted and reported the study according to Consolidated criteria for reporting qualitative

134 studies (COREQ). (Additional file 1: Table S1: COREQ checklist)[20]

\section{Analysis}

All interviews were conducted in the local language and then translated into English by a

137 professional translator. Interviews were digitally recorded and professionally transcribed verbatim.

138 Two experienced researchers, S Padmawati, Ph.D., Medical Anthropologist, and Dr. M Sitaresmi,

139 Ph.D. Pediatrician- public health researcher, independently analyzed the transcript manually and 140 constructed it, cross-checked, and finalized a code list of major themes. We analyzed and coded 141 all of the 26 transcripts using the final thematic framework.

\section{RESULTS}

144 All of 26 invited respondents (100\% response rate) consisted of 17 primary caregivers, 145 and nine pregnant women participated in in-depth interviews. Two of 17 parents (11\%) had 146 vaccinated their child with rotavirus vaccine. The mean ages of participants were 31 years (range: 14722 to 44 years old), 20 (77\%) of participants had completed at least senior high school, while 17 148 (65\%) were unemployed.

\section{General knowledge and attitude towards diarrhea}

150 The general knowledge of participants regarding diarrheal disease was fair. Changes in 
151 stool consistency, frequent defecation, abdominal pain, and dehydration were frequent symptoms

152 cited by participants. Participants recognized poor hygiene and sanitation, irregular eating 153 schedules, and eating the "wrong food" as causes of diarrhea. Improved sanitation and hygiene

154 behavior were reported as effective approaches to prevent diarrheal disease. They perceived the 155 use of Oral Rehydration Solution (ORS), increasing fluid intake, and continued breastfeeding as 156 effective treatments for diarrhea.

157 "Give Oralit [ORS] first. When still a baby, just give him enough breast milk because the baby has to breastfeed to prevent dehydration......If her condition becomes more severe, then consult the doctor" (Pregnant woman)

\section{Not a high health priority}

The low risk of acquiring diarrhea was a common emergent theme with diarrhea not perceived as a high-priority health issue for children. However, if not managed appropriately, participants did recognize that diarrhea could become a severe condition.

"I have already kept clean; my children do not get diarrhea. Just last time during the earthquake when it was dirty, now it is clean" (Mother of three children)

'Diarrhea is a mild disease. "Old people" said, if children get diarrhea, it's called ngentengngentengi (lighter), because he will be smart. However, it can also be severe diarrhea... If it continues, it will be serious" (Mother of two children).

170 stool, fever, or bloody stool. Most participants were aware of the need to present to HCPs if 171 diarrhea persisted or accompanied by vomiting, fever, or bloody stool.

172 "If no fever, it means mild, if defecation watery and frequently more than five times it is 173 severe, very severe if with blood, (child) should be brought to HCPS)" (Mother of two 174 children). 
After receiving information on the signs and symptoms of rotavirus diarrhea, the local term

176 muntaber (frequent vomiting and diarrhea) was associated as being rotavirus diarrhea. There was

177 a perception that muntaber was associated with serious diarrhea. However, the perception that

178 muntaber could be prevented by high sanitation and hygiene remained.

"Yes, muntaber is dangerous.. It will make the body weak and dehydrated" (Mother of a child aged)

"I am really worried about mutaber, but if we keep healthiness and clean, it will prevent the children from the disease." (Pregnant woman)

\section{Low awareness of the rotavirus vaccine}

Aside from the two mothers who had vaccinated their children against rotavirus, only one participant had heard of the rotavirus vaccine. In this case, the respondent had a family member

186 who had participated in a clinical trial for the RV3 rotavirus vaccine. After receiving information on

187 the rotavirus vaccine, most participants perceived that the vaccine is an important method to 188 prevent severe diarrhea. However, when asked about their intention to vaccinate their child, over

189 half indicated that they would vaccinate their child with rotavirus vaccine. Participants commonly

190 highlighted that they need to discuss it with their HCP before accepting the vaccine. Most 191 participants mentioned that they trust their HCP and will vaccinate their children according to their 192 HCP recommendation.

\section{Barriers to rotavirus vaccination}

We identified some concerns regarding the vaccine with consistently emerging themes

195 summarized in Table 2. The most common issue raised was that the vaccine was not included

196 in the Indonesian NIP. The parents perceived the vaccine as not being important as it is not

197 included in NIP. 

“... I will take the basics first (NIP vaccines), and I do not know about the other vaccines because it is not obligatory. If it is included in the basic vaccination, I will follow the recommendation" (Mother of two children)

202 Participants were concerned that the vaccine was too new and that there needed to be more 203 evidence of the vaccine's effectiveness and safety

We also identified that the cost of the vaccine was also a significant barrier. When asked

208 how much money they are willing to pay for the vaccine, the responses varied from US $\$ 1$ to 209 \$US25. In regards to the issue of the use of porcine trypsin, most participants stated that they are 210 willing to accept it as long as the vaccine has been 'washed' correctly, and it has been labeled as 211 halal (permitted) by the Indonesia Islamic organization, Council of Islam, Indonesia (MUI). "I think if it had been stated as halal by MUI the community would receive it" (Mother of three children)

\section{Desire to receive information}

215 Vaccine information and recommendations were mainly from primary HCPs, especially midwives.

216 However, they mentioned that their HCP provided limited information and only the recommended 217 vaccines on the NIP due to long waiting times and short consultations.

218 "...in the primary health center, if we do not ask, they do not give any information" (Mother 219 of two children)

220 "No, there was no explanation about immunization, yesterday was so crowded it was 221 already at ten o'clock and the queue was a lot, felt like in a hurry" (mother of a child) 
Other sources of information mentioned included healthcare volunteers (cadres), relatives,

223 friends, maternal-child health books, leaflets, and the Internet.

"I read from the maternal-child health book. I know it (rotavirus vaccine) from the leaflet, and then I asked to doctor" (Mother of a rotavirus vaccinated child)

226 Participants expressed a desire to receive more information about rotavirus disease and the

227 vaccine. Suggested methods for disseminating the information included a personal consultation

228 by primary HCPs, leaflets, and a group education session for pregnant women/new mothers.

229 Islamic leaders were also identified as an essential source for disseminating the information.

\section{DISCUSSION}

This study was exploring knowledge and attitudes towards rotavirus diarrhea and the

233 acceptance of the vaccine amongst primary caregivers in Yogyakarta, Indonesia. We found that

234 participants were not aware of the burden of rotavirus disease and the availability of the vaccine.

235 Diarrhea was perceived as not being a high health priority. Most of our parents believe their

236 children had a low susceptibility to the disease. They perceived that they could protect their child

237 from diarrhea if they maintained strict sanitation-hygiene behaviors and breastfed. This finding

238 was similar to the more recent multi-countries survey (2018), which involved 1500 participants,

239 including 250 parents from Indonesia. They reported that only $36 \%$ of Indonesian parents aware

240 that every child will be infected rotavirus by the age of 5 years[21]. Another study from a developed

241 country, Italy, assessed parent's knowledge, belief, and behavior toward rotavirus, and found that

242 less than half of their participants had heard about rotavirus infection and aware of the availability

243 vaccine[22]. Prioritizing the importance of rotavirus disease is the first step towards the successful

244 implementation of the vaccine[17]. Our participants perceived diarrhea as an accepted and 245 manageable disease. Increasing fluid intake and use of ORS were considered to be simple 
246 methods to manage diarrhea. While it appears that past efforts to educate the community about

247 the importance of preventing and managing classic diarrhea appear to have been successful, 248 renewed efforts are needed to establish the importance of rotavirus as a causative agent of 249 diarrhea. Compared to classic diarrhea, rotavirus diarrhea is significantly more severe due to the 250 increased risk of vomiting and difficulties in the administration of ORS. Besides, improvements in 251 sanitation and hygiene are not sufficient to prevent rotavirus disease; thus, vaccination is the most 252 effective prevention [9].

253 As the vaccine was not listed on the NIP, it was devalued by parents. This was intrinsically 254 linked to the idea that if the vaccine was not listed on the NIP, then the Indonesia Government 255 must not consider that the disease is essential. This concern was also raised by our HCPs[19] 256 and has been previously reported in connection with other vaccines, namely the pneumococcal 257 vaccine [23].

Concern regarding "the newness", safety, efficacy, and the cost of the vaccine were raised

259 by our participants as potential barriers for accepting the vaccine. These concerns have also been

260 cited as important barriers to the acceptance of other new vaccines [24], [25]. Other barriers are

261 the halal status and the use of porcine trypsin in the vaccine production process. This issue has 262 been previously reviewed by Grabenstein [26]. For most Muslims in Indonesia, halal is a 263 significant factor influencing their decision to vaccinate. Both Rotarix ${ }^{\circledR}$ and RotaTeq $^{\circledR}$ have yet to 264 been approved as halal vaccines by MUI. Previous experience with obtaining approval for the 265 polio vaccine highlights the importance of MUI endorsement of the rotavirus vaccine as a halal 266 vaccine[27]. Advocacy for the endorsement of new vaccines by Islamic Organizations should be 267 a critical component of an immunization strategy as parents need assurances that the vaccine is 268 halal[18].

269 Similar to a qualitative review by Ames HMR et al.[28], our participants expressed a desire 270 to receive more information about rotavirus disease and the vaccine. Knowledgeable of the 
271 disease and the vaccine will influence the acceptance of the vaccine. As with previous studies,

272 our study found that primary HCPs have an essential role in parental vaccine decisions[21], [29].

273 Clear communication between parents and their trusted HCP will influence vaccine acceptance.

274 Most participants reported that they received their information on vaccines from their primary

275 HCPs and that their primary HCPs influenced their decisions. However, the limited time spent

276 discussing the issue of immunization with parents (especially given that is a tendency to focus on

277 the vaccines listed on the NIP) along with the provider's lack of knowledge has been identified as

278 potential barriers in promoting the rotavirus vaccine[19]. In Indonesia, midwives provide most

279 childhood vaccines. However, according to Indonesian regulation, midwives are only permitted to

280 provide vaccines on the NIP[30]. Non-NIP vaccines are only available through hospitals or private

281 pediatricians[31]. The limited availability of the vaccine will continue to be a significant barrier for

282 parents who wish to vaccinate their children against rotavirus.

283 To our knowledge, no research focusing on the attitudes of Indonesian parents towards

284 the rotavirus vaccine. Using in-depth interviews to elicit a greater depth in the information is a key

285 strength of our work. Our study can identify the barriers of rotavirus vaccine acceptance. We

286 acknowledge that this result should not be generalized to a broader population due to the unique

287 characteristics of our study sample. We conducted interviews with a limited number of

288 participants, so other important themes in other populations cannot be ruled out. This qualitative

289 study should be complemented with a quantitative study with a representative sample of parents

290 to provide a comprehensive assessment of barriers to the implementation of the rotavirus vaccine

291 in Indonesia.

292

293 CONCLUSION 
294 There was low awareness of rotavirus being a serious disease and the rotavirus vaccine 295 availability in Indonesia. The vaccine is not on the Indonesian NIP, the newness, the safety and 296 efficacy, the cost, and the halal status of the vaccine were barriers to vaccine acceptance. 297 Information and recommendation by their HCP play an essential role in accepting the vaccine. 298 Discussion regarding rotavirus disease and the vaccine availability needs to be conducted with 299 communities, religious leaders, and HCPs

\section{$301 \quad$ List of abbreviations}

302 HCP: Health Care Provider; IRSN: Indonesian Rotavirus Surveillance Network, MUI: Majelis 303 Ulama Indonesia; MHREC: The Medical and Health Research Ethics Committee, NIP: National 304 Immunization Program; ORS: Oral Rehydration Solution; PHC: Primary Health Centre; WHO:

305 World Health Organization

\section{Declarations:}

307 Ethics approval and consent to participate: The Medical and Health Research Ethics 308 Committee (MHREC) FK-KMK UGM ((KE/FK/689/EC) and University of New South Wales, 309 Australia (HC13079) approved the study. We obtained informed consent from all participants at

310 the time of the interview, and we assured confidentially. We conducted and reported the study

311 according to Consolidated criteria for reporting qualitative studies (COREQ).

\section{Consent for publication: not applicable}

313 Availability of data and materials: The datasets used and/or analysed during the current 314 study are available from the corresponding author on reasonable request

\section{Conflict of interests}


316 HS has received grant funding for investigator-driven research from bioCSL, GSK, and Sanofi

317 Pasteur. AEH has received grant funding for investigator-driven research from GSK and Sanofi

318 Pasteur. CRM has received funding from GSK for investigator-driven research on vaccines.

319 The other authors have no competing interests to declare.

320 Funding: GlaxoSmithKline (GSK) Biologicals SA and GSK funded the study. No Grant:

321 No.176/SBP-Univ NSW-UGM/Research/VIII/13

322 The funders had no role in data collection, analyses, interpretation, or writing and are not

323 responsible for any statements or conclusions in this manuscript.

324 Author's Contributions

325 MNS, AEH, RSP, HS, and CRM developed the study design. MNS, RSP, JAT, and YS performed

326 data collection. MNS, RSP, HS contributed to the interpretation and data analysis. MNS

327 developed the main draft manuscript. All authors reviewed, gave comments, and approved the

328 final manuscript.

329 ORCID ID

330 Mei Neni Sitaresmi

ORCID ID: $\underline{0000-0002-2915-0307}$

331 Holly Seale

ORCID ID: $\underline{0000-0002-1877-5395}$

332 Anita Heywood

ORCID ID: $\underline{0000-0003-4400-7960}$

333 Siwi Padmawati

ORCID ID: $\underline{0000-0003-0744-5996}$

334 Yati Soenarto

ORCID ID: $\underline{0000-0003-4326-0649}$

335 C Raina Maclntyre

ORCID ID: $\underline{0000-0002-3060-0555}$

336 Jarir Atthobari

ORCID ID: $\underline{0000-0002-7035-4846}$

\section{Acknowledgments}


338 The authors would like to thank GlaxoSmithKline (GSK)BiologicalsSA and GSK Indonesia for

339 financial support in this study, Yoke Kinanthi Putri and Winda Yanuarni Meye as research 340 assistants, and also wish to thank the participants who took part in this study.

\section{REFERENCES}

343 1. Liu L, Oza S, Hogan D, Chu Y, Perin J, Zhu J, et al. Global, regional, and national causes of

344 under-5 mortality in 2000-15: an updated systematic analysis with implications for the

345 Sustainable Development Goals. Lancet. 2016;388:3027-35. doi:10.1016/S0140-

$346 \quad 6736(16) 31593-8$.

347 2. Troeger C, Forouzanfar M, Rao PC, Khalil I, Brown A, Reiner RC, et al. Estimates of global, 348 regional, and national morbidity, mortality, and aetiologies of diarrhoeal diseases: a systematic 349 analysis for the Global Burden of Disease Study 2015. Lancet Infect Dis. 2017;17:909-48. 350 doi:10.1016/S1473-3099(17)30276-1.

351 3. Clark A, Black R, Tate J, Roose A, Kotloff K, Lam D, et al. Estimating global, regional and 352 national rotavirus deaths in children aged $<5$ years: Current approaches, new analyses and 353 proposed improvements. PLoS One. 2017;12:1-18. doi:10.1371/journal.pone.0183392.

354 4. Hakim MS, Nirwati H, Aman AT, Soenarto $Y$, Pan Q. Significance of continuous rotavirus and 355 norovirus surveillance in Indonesia. World J Pediatr. 2018;14:4-12. doi:10.1007/s12519-018$356 \quad 0122-1$.

357 5. Nirwati H, Wibawa T, Aman AT, Wahab A, Soenarto Y. Detection of group A rotavirus strains 358 circulating among children with acute diarrhea in Indonesia. Springerplus. 2016;5:1-6. 359 doi:10.1186/s40064-016-1724-5.

360 6. Nirwati H, Hakim MS, Aminah S, Dwija IBNP, Pan Q, Aman AT. Identification of Rotavirus 
361 Strains Causing Diarrhoea in Children under Five Years of Age in Yogyakarta, Indonesia.

362 Malays J Med Sci. 2017;24:68-77. doi:10.21315/mjms2017.24.2.9.

363 7. Parwata WSS, Sukardi W, Wahab A, Soenarto Y. Prevalence and clinical characteristics of 364 rotavirus diarrhea in Mataram, Lombok, Indonesia. Paediatr Indones. 2016;56:118.

365 doi:10.14238/pi56.2.2016.118-23.

366 8. Wilopo SA, Kilgore P, Kosen S, Soenarto Y, Aminah S, Cahyono A, et al. Economic

367 evaluation of a routine rotavirus vaccination programme in Indonesia. Vaccine. 2009;27 SUPPL.

368 5:67-74. doi:10.1016/j.vaccine.2009.09.040.

369 9. Crawford SE, Ramani S, Tate JE, Parashar UD, Svensson L, Hagbom M, et al. Rotavirus 370 infection. JAMA Pediatr. 2018;172 SUPPL. 3:50-3. doi:10.1097/INF.0b013e3181967bee.

371 10. Richard L. Guerrant, Mark D. DeBoer, Sean R. Moore, Rebecca J. Scharf and AAML. The 372 impoverished gut-a triple burden of diarrhoea, stunting and chronic disease. Nat Rev

373 Gastroenterol Hepatol. 2013;10:220-9. doi:10.1038/nrgastro.2012.239.

374 11. Pinkerton R, Oriá RB, Lima AAM, Rogawski ET, Oriá MOB, Patrick PD, et al. Early 375 childhood diarrhea predicts cognitive delays in later childhood independently of malnutrition. Am 376 J Trop Med Hyg. 2016;95:1004-10. doi:10.4269/ajtmh.16-0150.

377 12. Wierzba TF, Muhib F. Exploring the broader consequences of diarrhoeal diseases on child 378 health. Lancet Glob Heal. 2018;6:e230-1. doi:10.1016/S2214-109X(18)30047-0.

379 13. States M, Strategic WHO, Group A, Who A, Le E. Rotavirus vaccines WHO position paper:

380 January 2013 - Recommendations. Vaccine. 2013;31:6170-1.

381 doi:10.1016/j.vaccine.2013.05.037.

382 14. (IVAC) internationalVaccineAccessCenter. A report on current global access to new 383 vaccines VIMS Report : Global Vaccine Introduction. 2019. https://view- 
384 hub.org/sites/default/files/2020-05/VIEW-hub_Report_Jun2019_0.pdf Accessed 21 Nov 2020

385 15. Debellut F, Clark A, Pecenka C, Tate J, Baral R, Sanderson C, et al. Re-evaluating the 386 potential impact and cost-effectiveness of rotavirus vaccination in 73 Gavi countries: a modelling 387 study. Lancet Glob Heal. 2019;7:e1664-74. doi:10.1016/S2214-109X(19)30439-5.

388 16. Soares-Weiser K, Bergman H, Henschke N, Pitan F, Cunliffe N. Vaccines for preventing 389 rotavirus diarrhoea: Vaccines in use. Cochrane Database Syst Rev. 2019;2019.

390 doi:10.1002/14651858.CD008521.pub4.

391 17. World Health Organization. Vaccine Introduction Guidelines: adding a vaccine to a national 392 immunization programme: decision and implementation. 2005.

393 https://apps.who.int/iris/bitstream/handle/10665/111548/9789241506892_eng.pdf;jsessionid=9F

394 EC303EBF40BE25606BD3C6B23E83E3?sequence=1 Accessed 24 Dec 2020

395 18. Padmawati RS, Heywood A, Sitaresmi MN, Atthobari J, Maclntyre CR, Soenarto Y, et al.

396 Religious and community leaders' acceptance of rotavirus vaccine introduction in Yogyakarta, 397 Indonesia: A qualitative study. BMC Public Health. 2019;19:1-6. doi:10.1186/s12889-019-67063984.

399 19. Seale H, Sitaresmi MN, Atthobari J, Heywood AE, Kaur R, Maclntyre RC, et al. Knowledge 400 and attitudes towards rotavirus diarrhea and the vaccine amongst healthcare providers in 401 Yogyakarta Indonesia. BMC Health Serv Res. 2015;15. doi:10.1186/s12913-015-1187-3.

402 20. Tong A, Sainsbury P, Craig J. Consolidated criteria for reporting qualitative research 403 (COREQ): A 32-item checklist for interviews and focus groups. Int J Qual Heal Care. 404 2007;19:349-57. doi:10.1093/intqhc/mzm042.

405 21. Benninghoff B, Pereira P, Vetter V. Role of healthcare practitioners in rotavirus disease 406 awareness and vaccination-insights from a survey among caregivers. Hum Vaccines 407 Immunother. 2020;16:138-47. doi:10.1080/21645515.2019.1632685. 
408 22. Napolitano F, Adou AA, Vastola A, Angelillo IF. Rotavirus infection and vaccination:

409 Knowledge, beliefs, and behaviors among parents in Italy. Int J Environ Res Public Health.

$410 \quad$ 2019;16. doi:10.3390/ijerph16101807.

411 23. Harjaningrum AT, Kartasasmita C, Orne-Gliemann J, Jutand MA, Goujon N, Koeck JL. A

412 qualitative study on knowledge, perceptions, and attitudes of mothers and health care providers

413 toward pneumococcal conjugate vaccine in Bandung, West Java, Indonesia. Vaccine.

414 2013;31:1516-22. doi:10.1016/j.vaccine.2013.01.007.

415 24. Oldin C, Golsäter M, Schollin Ask L, Fredriksson S, Stenmarker M. Introduction of rotavirus

416 vaccination in a Swedish region: assessing parental decision-making, obtained vaccination

417 coverage and resulting hospital admissions. Acta Paediatr Int J Paediatr. 2019;108:1329-37.

418 doi:10.1111/apa.14674.

419 25. Apte A, Roy S, Bavdekar A, Juvekar S, Hirve S. Facilitators and barriers for use of rotavirus

420 vaccine amongst various stakeholders and its implications for Indian context-A systematic

421 review. Human Vaccines and Immunotherapeutics. 2018;14:2760-7.

422 doi:10.1080/21645515.2018.1489190.

423 26. Grabenstein JD. What the World's religions teach, applied to vaccines and immune

424 globulins. Vaccine. 2013;31:2011-23. doi:10.1016/j.vaccine.2013.02.026.

425 27. Majelis Ulama Indonesia (MUI) ((lit. Indonesian Uelama Council). Fatwa penggunaan vaksin

426 polio khusus (IPV) (Fatwa on the use of special polio vaccines). 2002. http://mui.or.id/wp-

427 content/uploads/files/fatwa/Penggunaan-Vaksin-Polio-Khusus.pdf Accessed 24 Nov 2020

428 28. Lugg F V., Butler CC, Evans MR, Wood F, Francis NA. Parental views on childhood

429 vaccination against viral gastroenteritis-a qualitative interview study. Fam Pract. 2015;32:456-

430 61. doi:10.1093/fampra/cmv035.

431 29. George MS, Negandhi P, Farooqui HH, Sharma A, Zodpey S. How do parents and 
432 pediatricians arrive at the decision to immunize their children in the private sector? Insights from

433 a qualitative study on rotavirus vaccination across select Indian cities. Hum Vaccines

434 Immunother. 2016;12:3139-45. doi:10.1080/21645515.2016.1219824.

435 30. Ministry of Health Indonesi. Peraturan Menteri kesehatan republik Indonesia no 28 tahun

4362017 tentang izin dan penyelenggaraan praktik bidan (Regulation of Ministry of Health The

437 Republic of Indonesia about licencing and conducting practices for midwives). 2017.

438 http://www.ibi.or.id/media/PMK No. 28 ttg Izin dan Penyelenggaraan Praktik Bidan.pdf

439 Accessed 24 Dec 2020

440 31. Ministry of Health Indonesia. Peraturan Menteri Kesehatan Republik Indonesia, nomer 12

441 tahun 2017 tentang penyelenggaraan Imunisasi (Regulation of $\mathrm{MOH}$ the Republic of Indonesia

442 number 12 year 2017 about immunization implementation. 2017.

443 http://hukor.kemkes.go.id/uploads/produk_hukum/PMK_No._12_ttg_Penyelenggaraan_Imunisa

444 si_.pdf Accessed 24 Dec 2020 
446 Table 1: Consolidated criteria for reporting qualitative studies (COREQ): 32-item

447 checklist

448

449 Developed from:

450 Tong A, Sainsbury P, Craig J. Consolidated criteria for reporting qualitative research (COREQ):

451 a 32-item checklist for interviews and focus groups. International Journal for Quality in Health

452 Care. 2007. Volume 19, Number 6: pp. $349-357$

No. Item Guide questions/description $\quad$ Reported on Page \#

\section{Domain 1: Research team and reflexivity}

\section{Personal Characteristics}

1. Inter viewer/facilitator

Which author/s conducted the interview or

Methods: data collection focus group?

page 6 , paragraph 1

2. Credentials

What were the researcher's credentials?

Methods: analysis

E.g. PhD, MD

page 6 , paragraph 2

3. Occupation

What was their occupation at the time of

Methods: analysis

the study?

page 6, paragraph 2 .

4. Gender

Was the researcher male or female?

Methods: data collection

\& analysis

page 6, paragraph $1 \& 2$.

5. Experience and training What experience or training did the

Methods: data collection

researcher have?

\& analysis

page 6, paragraph 2 . 


\begin{tabular}{|c|c|c|}
\hline 6. Relationship established & $\begin{array}{l}\text { Was a relationship established prior to } \\
\text { study commencement? }\end{array}$ & $\begin{array}{l}\text { Methods: participants and } \\
\text { recruitment } \\
\text { page } 5 \text {, paragraph } 3 \text {. }\end{array}$ \\
\hline $\begin{array}{l}\text { 7. Participant knowledge of } \\
\text { the interviewer }\end{array}$ & $\begin{array}{l}\text { What did the participants know about the } \\
\text { researcher? e.g. personal goals, reasons } \\
\text { for doing the research }\end{array}$ & $\begin{array}{l}\text { Methods: participants } \\
\text { and recruitment } \\
\text { page } 5 \text {, paragraph } 3 \text {. }\end{array}$ \\
\hline $\begin{array}{l}\text { 8. Interviewer } \\
\text { characteristics }\end{array}$ & $\begin{array}{l}\text { What characteristics were reported about } \\
\text { the inter viewer/facilitator? e.g. Bias, } \\
\text { assumptions, reasons and interests in the } \\
\text { research topic }\end{array}$ & $\begin{array}{l}\text { Methods: data collection } \\
\text { page } 6 \text {, paragraph } 2 \text {. }\end{array}$ \\
\hline
\end{tabular}

\section{Domain 2: study design}

Theoretical framework

9. Methodological

orientation and Theory
What methodological orientation was

stated to underpin the study? e.g.

grounded theory, discourse analysis,

ethnography, phenomenology, content

analysis

\section{Methods: analysis}

page 6, paragraph 2.

\section{Participant selection}

10. Sampling

How were participants selected? e.g.

Methods: participants and

purposive, convenience, consecutive,

recruitment

snowball

page 5, paragraph 3.

11. Method of approach

How were participants approached? e.g.

face-to-face, telephone, mail, email

Methods: participants and

recruitment

page 5, paragraph 3 .

12. Sample size

Results 
page 7 , paragraph 1

13. Non-participation

How many people refused to participate or

Results

dropped out? Reasons?

page 7 , paragraph 1

\section{Setting}

14. Setting of data

collection

15. Presence of non-

participants

16. Description of sample
Where was the data collected? e.g. home,

clinic, workplace

Was anyone else present besides the

participants and researchers?

What are the important characteristics of

the sample? e.g. demographic data, date
Methods: data collection

page 6, paragraph 1 .

Methods, data collection

page 6, paragraph 1 .

Results

page 7 , paragraph 1.

\section{Data collection}

\section{Interview guide}

18. Repeat interviews

20. Field notes

21. Duration

22. Data saturation

23. Transcripts returned
Were questions, prompts, guides provided

by the authors? Was it pilot tested?

Were repeat interviews carried out? If yes, how many?

Did the research use audio or visual recording to collect the data?

Were field notes made during and/or after the inter view or focus group?

What was the duration of the inter views or focus group?

Was data saturation discussed?

Were transcripts returned to participants for comment and/or correction?
Methods: data collection

page 6, paragraph 1.

Repeat interviews were not carried out.

Methods: analysis

page 6, paragraph 2 .

Methods: analysis

page 6, paragraph 2 .

Methods: data collection page 6, paragraph 1.

Methods: data collection page 6, paragraph 1 .

Methods: data collection page 6, paragraph 1. 


\section{Domain 3: analysis and findings}

Data analysis

24. Number of data coders How many data coders coded the data? Methods: analysis

page 6, paragraph 2.

25. Description of the

coding tree

26. Derivation of themes

27. Software

28. Participant checking
Did authors provide a description of the coding tree?

Were themes identified in advance or derived from the data?

What software, if applicable, was used to manage the data?

Did participants provide feedback on the findings?
$\mathrm{N} / \mathrm{A}$

Methods: analysis page 6, paragraph 2 .

NA

Methods: data collection page 6, paragraph 1 .

\section{Reporting}

29. Quotations presented

Were participant quotations presented to

Results

illustrate the themes/findings? Was each

quotation identified? e.g. participant

number

30. Data and findings

Was there consistency between the data

Yes

consistent

presented and the findings?

31. Clarity of major themes Were major themes clearly presented in the findings?

Themes are outlined in the discussion section

32. Clarity of minor themes Is there a description of diverse cases or Yes included in the discussion of minor themes? 
- Respondents were not aware of the burden of diarrheal disease.

- Respondents did not perceive their child susceptible of acquiring diarrhea. Improving sanitation-hygiene behaviors and providing breastfeeding were believed to protect from diarrhea sufficiently.

- Rotavirus diarrhea is an almost unknown disease. After receiving information about rotavirus, it was perceived as a serious disease.

- Rotavirus vaccine was acceptable especially if the vaccine is included in the NIP

- Concerns regarding rotavirus vaccine included not being on the Indonesian NIP, the "newness" of the vaccine, the potential for adverse events, the cost of vaccine, and the use of trypsin porcine in the vaccine production process.

- Respondents conveyed their desire for the Halal label to be clearly stated in the vaccine information sheet provided to parents

- Respondents reported the need for more information on rotavirus disease and the vaccine and that further discussion with primary health providers was essential before accepting the vaccine for their children. 


\title{
PARTICIPANT INFORMATION STATEMENT AND CONSENT FORM
}

\author{
Research Project Title: Rotavirus Vaccine Acceptability Study \\ Principal Researcher: Dr Mei Neni Sitaresmi and Dr Jarir At Thobari (Indonesia) \\ Dr Holly Seale and Dr Anita Heywood (Australia)
}

\section{What is an Information Statement?}

Thank you for taking the time to read this Information Statement. It provides information about a new study that is being conducted by the Universitas Gadjah Mada and the University of New South Wales.

473 The information provided in this document is to help you to decide whether or not you would like to take 474 part in the research.

Please read this information statement carefully. If you have any questions about the study, please ask the 476 study team member.

Once you have understood what the project is about you will be asked whether you wish to take part. If you agree, you will be asked to sign the consent form on page 4 . By signing the consent form you indicate that you understand the information and want to participate in the research project.

You will be given a copy of this information and consent form to keep.

\section{What is the research about?}

\section{Background}

484 Rotavirus is the most common cause of severe gastroenteritis and dehydration in young children in both low and high resource countries. Efforts to prevent disease by improving sanitation alone have not reduced the rotavirus disease burden and it remains a significant cause of child mortality and hospitalisation in Indonesia. A vaccine to prevent rotavirus is available and the first dose is given to infants between 6 and 14 weeks of age.

\section{What is the purpose of this study?}

This study aims to identify the attitudes and barriers to acceptance of rotavirus vaccine among parents/primary caregivers, vaccine providers, community/village leaders, policy makers and Religious Leaders in Yogyakarta, Indonesia.

\section{How many people will be involved in this study?}

Participants will consist of parents, grandparents, healthcare workers, community/village leaders, policy makers and Religious Leaders.

\section{Which institutions are supporting this research project?}

The study is being run by the Paediatric Research Office Dr. Sardjito Hospital/Faculty of Medicine Gadjah 503 funding for this study is provided by GlaxoSmithKline, a vaccine manufacturer. 


\section{Why am I being asked to be in this research project?}

Based on information from the primary health centre or from publically availably information, you have been identified as being eligible for our study.

\section{What do I need to do to be in this research project?}

If you agree to participate, you will be asked to complete a short (5 minute) survey that will collect general demographic information. This information will be used to generally describe the study population and their level of experience in any published work. After that, we would like to complete one interview with you to examine your views on the disease and the vaccine. The interview will take 30 minutes to complete and will be scheduled at a time which is convenient to you. You can stop the interview at any time or can leave questions you don't want to answer.

\section{What are my alternatives to taking part in this study?}

It is up to you to decide whether or not to take part and no one force you to do so. Your consent and participation in this study is voluntary. You are free to withdraw at any time, without giving a reason. If you decide to withdraw, please let me know. Deciding not to take part in the study or withdrawing during the study will have no impact on your or your children's care through your Primary Health Centre or your relationship with The University of New South Wales or Universitas Gadjah Mada, Indonesia.

\section{What are the possible benefits for me?}

We cannot and do not guarantee or promise that you will receive any benefits from this study.

\section{What are the benefits to other people in the future?}

We hope that the rotavirus vaccine will be accepted by the community and prevent many of deaths and hospitalisations caused by rotavirus every year.

\section{What are the possible risks?}

We do not anticipate any risks to you from being in this study. Some questions ask about your attitudes towards rotavirus and the vaccine in a way that you may not have considered before. Thinking about some of these issues may make you worry or feel uncomfortable. If you do feel this way, please speak to the study investigator.

\section{What will be done to make sure my information is confidential?}

Any information that is obtained in connection with this study and that can be identified will remain confidential and will be disclosed only with your permission, except as required by law. We plan to publish the outcomes of the research in peer-reviewed journal papers. In any publication, information will be presented in such a way that you will not be able to be identified.

\section{Will there be any financial cost or reimbursement for participating in this research project?}

There will be no compensation provided to you, but transportation costs will be reimbursed.

\section{Who can I contact about the study?}

If you would like more information about the project or if you need to speak to a member of the research team, you can contact the research team as follows:

Complaints may be directed to:

Indonesia: Ethics Secretariat, Faculty of Medicine Gadjah Mada University (Tel. 9017225 or 0274-7134955, email mhrcc fmugm@ugm.ac.id

Australia: Ethics Secretariat, The University of New South Wales, SYDNEY 2052 AUSTRALIA (Tel: 612 9385 4234, fax 9385 6648, email ethics.gmo@unsw.edu.au).

Any complaint you make will be investigated promptly and you will be informed out the outcome. 
Principal Investigators

560 Indonesia

561 Name: Dr. Mei Neni Sitaresmi, Ph.D, SpA(K) or Dr. Jarir At Thobari, Ph.D.

562 Office name: Paediatric Research Office

563 Addres: jl. Kesehatan No. 1, Sekip, Yogyakarta, Indonesia

564 Phone: $\quad$ (0274)561616 or (0274) 587333 ext 543.

$565 \quad$ Email: $\quad$ msitaresmi@yahoo.com or j.atthobari@gmail.com

566

567

568

569

570

571

572

573

\title{
Australia
}

Name: $\quad$ Dr. Holly Seale or Dr. Anita Heywood

Office name: School of Public Health and Community Medicine, University of New South Wales

Address: $\quad$ Level 3, Samuels Building, UNSW, Sydney, NSW 2052

Phone: $\quad+61293853667$

Email: $\quad$ h.seale@unsw.edu.au or a.heywood@unsw.edu.au

574

\author{
THE UNIVERSITY OF NEW SOUTH WALES \\ SYDNEY, AUSTRALIA
}

UNIVERSITAS GADJAH MADA

YOGYAKARTA, INDONESIA

\section{PARTICIPANT INFORMATION STATEMENT}

Rotavirus Vaccine Acceptability Study

I have read the information provided above. I understand the purpose, extent and possible effects in this

585 By signing this form, I decide to participate.

586 Date

588 Signature

589 Name

593 Signature of witness

594 Name of witness 
THE UNIVERSITY OF NEW SOUTH WALES

SYDNEY, AUSTRALIA

\section{UNIVERSITAS GADJAH MADA}

YOGYAKARTA, INDONESIA

596

597

PARTICIPANT INFORMATION STATEMENT

598

Rotavirus Vaccine Acceptability Study

599

600

601 I hereby wish to WITHDRAW my consent to participate in the research proposal described above and 602 understand that such withdrawal WILL NOT jeopardize any relationship with The University of New South 603 Wales or Universitas Gadjah Mada, Indonesia.

604

605

606

607

608 Signature

Date

609

610

611

612

613 Name

614

615

616

617

618

619

The section for Revocation of Consent should be forwarded to: Dr Mei Neni Sitaresmi, Pediatric

Research Office, Pediatric Department, Faculty Medicine, Universitas Gadjah Mada, Jl, Kesehatan No. 1

620

621

622

623 


\section{Interview guide}

626 Knowledge and attitudes towards rotavirus diarrhea and the acceptance of

627 rotavirus vaccination amongst primary caregivers in Yogyakarta, Indonesia: a

628 qualitative study

629 Mei N. Sitaresmi ${ }^{a, g}$, Holly Seale ${ }^{b}$, Anita E. Heywood ${ }^{C}$, Retna S. Padmawatid, Yati

630 Soenarto $^{a}$, C Raina Maclntyre ${ }^{e}$, Jarir Atthobarif

633 What do you know about diarrhoea? (Probes: symptoms, diagnosis, treatment, 634 complications, prevention) What are the reasons for developing diarrhoea? How 635 serious can the consequences of diarrhoea be? What should be done to prevent 636 diarrhoea in children?

638 Have you ever heard about diarrhoea caused by RV (If no, the interviewer should 639 explain about the symptom, to understand whether there are local concepts on the 640 illness)? Is there any other word that you use to describe or call the symptoms in your 641 local terminology/ language?

642 How concerned are you about your child becoming infected with rotavirus?

643 [Skip for women pregnant with $1^{\text {st }}$ child] Have your child(ren) ever had RV diarrhoea?

644 (please mention the symptoms in case the informant does not know about RV). If yes, 645 how did you know it was RV diarrhoea? (by HCP, leaflet, other media?) 
646 Have you ever heard about rotavirus vaccine? If your child's doctor recommended a

647 vaccination for your child against a virus that causes diarrhoea (RV), how likely would

648 you be to vaccinate your child? Would you accept your health care provider

649 recommendations for vaccination of your child/children? Why or why not? What would

650 you want to know about the virus or the vaccination? From whom would you prefer this

651 information from?

652 What issues would concern you when deciding whether or not to vaccinate your child

653 against this virus that causes diarrhoea? What would convince that this vaccine is very

654 important for your child/children? What would influence you to refuse having your

655 child/children vaccinated against this virus?

656 How much would you be willing to pay for the vaccine?

657

658 Have you ever looked for information about rotavirus or about the rotavirus vaccine

659 from any source?

660 If yes, on the most recent time you looked for information, where did you go first? What

661 did you think about the quality of the information?

662 If no, imagine then that you had a strong need to get information about rotavirus. Where 663 would you go first? Which additional information would you like most to have on rotavirus 664 or the vaccine?

665

666 Is there any other information regarding this topic you would like to add? 667 


\section{Supplementary Files}

This is a list of supplementary files associated with this preprint. Click to download.

- InterviewguideBMC.docx

- Informationstatement.docx 